\title{
Efficacy of Mastery-Based Adaptive Technology in Introductory Quantitative Reasoning Course
}

\author{
Santhosh Mathew* \\ Department of STEM, Regis College, 235 Wellesley Street, Weston, MA-02943, USA \\ E-mail: santhosh.mathew@regiscollege.edu \\ Upasana Kashyap \\ Department of STEM, Regis College, 235 Wellesley Street, Weston, MA-02943, USA \\ E-mail: upasana.kashyap@regiscollege.edu
}

\begin{abstract}
In this study, we explored the efficacy of using Hawkes Learning, a mastery-based adaptive technology system in a freshmen level Quantitative Reasoning course at a four-year private university. Students used this competency based adaptive platform to master the content by learning the material at their own pace, then practicing the problems and finally getting certified on their homework assignments. Each topic of this system offered three intuitive modes to mastery: Learn, Practice, and Certify. We analyzed students' performance and perceptions with this system and compared it with the previous traditional model. Our study indicated that there is no statistically significant difference between students' performance but their perceptions towards learning have improved significantly when they used this technology. We found that most students were able to succeed in QR course with this technology and it enabled them to become better independent learners.
\end{abstract}

Keywords: Mastery-Based Learning, Adaptive Technology, Digital Learning, Quantitative Reasoning, Introductory Mathematics Course

DOI: $10.7176 / \mathrm{JEP} / 10-24-02$

Publication date: August 31st 2019

\section{Introduction}

\section{1 Background of the Study}

The web based learning systems have undergone several changes over the years and adaptive technology is one of the many facets of these systems. Adaptive Learning systems are digital learning systems that can change dynamically to benefit the students' learning in response to data collected during the course (U.S. Department of Education, Office of Educational Technology, 2013). It does not count other factors such as pre-existing information, for example learner's gender, age, or achievement test score. As the learners work with assignment, these systems use information gained during the process that include the way a concept is represented, its difficulty, the sequencing of problems or tasks, and the nature of hints and feedback provided

Adaptive technology has been gaining momentum in higher education as a tool to engage students and improve the learning outcomes. It has been reported that this approach provides more control for students as they can focus on what they do not know rather than what they already know (Johnson, 2016). Additional benefits include more engagement, long-term learning, higher confidence and improved results.

Regis College is a leading catholic university in United States devoted to engagement, service and advancement in a global community. Regis enrolls approximately 1,200 undergraduates annually, and is a leader in providing educational opportunity to first-generation and minority students. The Regis student body comprised of 20 percent male and 80 percent female with approximately 30 percent of students representing minority and international populations; and 25 percent are first-generation college students. Over 95 percent of students receive some form of financial aid at Regis. Many of our freshmen students are underprepared to be successful in college level Mathematics, which adversely affects their degree completion. For example, only 4.5 percent of our first year students have taken AP Calculus, compared to the average of 30 percent among all respondents to the CIRP Freshman Survey (Pryor et al, 2012). The STEM department at Regis College has been working to improve the performance of students especially in entry-level Mathematics courses, typically taken in the first year. Over the years, only about 70 percent of our freshmen student population has successfully completed the entry-level Mathematics courses in the first attempt. At Regis, Quantitative Reasoning (QR) is the entry-level foundational Mathematics course taken by more than 80 percent of freshmen students. According to Elrod (2014), QR is primarily the application of basic mathematical skills, such as algebra, to the analysis and interpretation of realworld quantitative information in the context of a discipline or an interdisciplinary problem to draw conclusions that are relevant to students in their daily lives. After the successful completion of QR course, students continue to pursue other Mathematics courses such as Statistics or Calculus as a part of general education Mathematics core requirements. 


\subsection{Statement of the Problem}

Similar to many other institutions of higher education, Regis has introduced several tools to help student succeed in QR course. One of such means is the introduction of mastery-based adaptive technology. In Fall 2017, we introduced Hawkes Learning system in QR course and in subsequent semesters we collected the data from this course regarding students' performance and perceptions. The Hawkes Learning mastery-based approach provides in-depth and meaningful feedback for students, encouraging a profound understanding of the curriculum and building confidence in their learning (Hawkes Learning, n.d.). Prior to the introduction of this technology in QR course, we used a traditional approach in teaching this course. It was primarily a lecture-based system with students completing their homework online using MyMathLab (MyMathLab, 2014) designed by Pearson Education to accompany its published Mathematics textbooks.

The student perceptions as reflected in course evaluations were poor in regards to MyMathLab homework system as they faced multiple challenges in completing the homework assignments. As a result, the overall passing rate was low for this course. Additionally, providing feedback with the traditional approach was not a seamless approach and students faced many technical problems in navigating the system. As an institution driven by studentcentered teaching and innovation, we decided to adopt an interface that better engages students and lead them to mastery through learn, practice and certify model. In addition, we wanted to have system in which feedback is proactive rather than reactive as even well-prepared students need intervention at the right time in Mathematics.

In this study, we report our results that compared the student performance in QR course from two different periods-one from Fall 2015 to Spring 2017 (pre-adaptive group when they used MyMathLab as online homework platform) and Fall 2017 to Spring 2019 (adaptive group when they used Hawkes Learning system). The enrollment number for pre-adaptive group and adaptive groups were 494 and 428 respectively. As mentioned earlier, the purpose of this investigation was to examine the extent to which this adaptive technology benefited college students in Quantitative Reasoning course at our institution.

\section{Literature Review}

In many college classrooms, it is a great challenge for instructors to know how well students are absorbing new concepts. Arizona State University has collaborated with Knewton (2019) to turn its classrooms into laboratories using "adaptive learning" method that provides instructors real-time intelligence on how well each of their students is getting each concept (Kolowich, 2013). In 2011, the university has placed 5,000 first-year students into remedial Mathematics courses powered by Knewton. It has been reported that the passing rates for these courses jumped from 66 percent to 75 percent.

Many U.S. colleges and universities recognized that a one-size-fits-all learning approach is not working in various classrooms as students come with a different level of mathematical ability, and adaptive learning technology solutions have shown positive results in student learning and success. Utilizing the advantages of personalized learning content, Colorado Technical University (CTU) began piloting courses in 2012 with the adaptive learning platform called intellipath. With improved student success in terms of grades, engagement, and retention, CTU has won several awards for its adaptive learning platform (Johnson, 2016).

As another example, Black Hills State University (BHSU) reported a 21\% increase in passing rate, a 300\% increase in enrollment in the next Mathematics course, a $25 \%$ improvement in attendance, and a statistically significant increase in Collegiate Assessment of Academic Proficiency (CAAP, a nationally normed test) scores when they redesigned college algebra to use the computer-based mastery learning program, Assessment and Learning in Knowledge Spaces (ALEKS) (Hagerty, Smith, \& Goodwin, 2010).

Similarly, a pilot program in online adaptive learning using ALEKS at UC Santa Cruz reported a higher placement in Mathematics courses for freshman students who completed placement test via online assessment and made use of adaptive learning software to review and reassess during the summer. The use of ALEKS reduced the number of students needing College Algebra and Pre-calculus without jeopardizing their success in Mathematics, and expedited the time to graduation, and improved retention and graduation rates, particularly for those in Science, Technology, Engineering, and Mathematics (STEM) fields (O'Neil, 2016).

\section{Method of Study}

The data for this study was collected from 922 students who took Quantitative Reasoning Course at Regis College from Fall 2015 to Spring 2019. There were several sections of this course that were taught by different experienced instructors but all used a common syllabus, grading criteria, instructional methods and resources for QR course. The tests, quizzes and homework assignments were also identical in content. Assignments were given for each section/lesson of the text and required to be completed before the next class period. The tests and quizzes were completed in class proctored by the instructors throughout the semester. The final course grade for each student was calculated at the end of the semester. This was calculated using weighted average formula comprising quizzes (15 percent), two semester tests (40 percent), online homework (20 percent), attendance and class participation (5 percent) and the final exam (20 percent). The QR course coordinator convened monthly meetings with all QR 
instructors to make sure all sections are following a uniform structure explicitly mentioned in the syllabus and to discuss the progress and concerns they had in their classes.

Among the above students, 494 of them were enrolled in QR course between Fall 2015 and Spring 2017 before we rolled out the adaptive technology and they used the MyMathLab as their homework platform. The textbook used for this course was "Using and Understanding Mathematics: A Quantitative Reasoning Approach by Bennet and Briggs" (Bennet \& Briggs, 2014). Students completed their homework assignments using the Pearson online homework module MyMathLab (Pearson Education, 2014). The remaining 428 students from the sample were enrolled between Fall 2017 and Spring 2019 and they used the newly introduced adaptive technology in their curriculum. The textbook used for adaptive group was "Viewing Life Mathematically: A Pathway to Quantitative Literacy, by Denley and Hall, Published by Hawkes Learning” (Denley \& Hall, 2016). These students completed their homework assignments using the Hawkes Learning adaptive technology.

The Hawkes Learning system (purchased along with digital or hard copies of the text), a mastery based adaptive platform, was a required component of QR course. Each topic from this system offered three modes to mastery: Learn, Practice, and Certify.

1. Learn is an interactive presentation of the material found in the textbook and includes instructional video clips and example problems.

2. Practice gives students access to unlimited practice problems, provides error specific feedback for commonly made mistakes, hints for all incorrect answers, and includes an interactive tutor with step-by-step guidance and fully worked out solutions. Note that every question type from Certify can be found in the Practice mode.

3. Certify is the homework portion of the lesson. After answering the set of questions without exceeding the available strikes (or lives), students will receive a perfect $100 \%$ score for their homework. If students are not able to Certify in their attempt, they were able to start a new set of questions over again with no penalty. In the meantime, they may wish to spend more time in the Practice mode before attempting Certify again. Students have unlimited attempts in each lesson to receive full credit before the due date. If a student has a problem with an assignment, they should immediately get help from the instructor, and/or from the on-campus Learning Center where students can get individual tutoring services free of cost

\section{Results and Discussion}

\subsection{Study Findings}

The results of this study are given in Table 1 below.

Table 1: Student performance in pre-adaptive and adaptive QR Courses

\begin{tabular}{|l|l|l|l|l|}
\hline Course Mode & Sample Size & $\begin{array}{l}\text { Number of students who } \\
\text { achieved a course average } \\
\text { of 70 or higher }\end{array}$ & $\begin{array}{l}\text { Percentage of students who } \\
\text { achieved a course average of } \\
70 \text { or higher }\end{array}$ & P-value \\
\hline Pre-Adaptive & 494 & 349 & 70.65 & 0.4034 \\
\hline Adaptive & 428 & 313 & 73.13 & \\
\hline
\end{tabular}

As can be seen from above table, the adaptive students had a slightly better passing rate $(73.13 \%)$ in the QR course compared to the pre-adaptive group $(70.65 \%)$. We conducted two sample independent test to compare the passing rates of these groups using statistical software SPSS (Version 24). Null hypothesis stated that both percentages are same and alternate hypothesis stated that they are different. Our Test results: $\mathrm{z}$ - test statistic $\mathrm{z}=$ $0.8356, \mathrm{p}$-value $=0.4034$. Because $\mathrm{p}$-value $>0.05$, we failed to reject null hypothesis. Based on this test, we concluded that there is no statistically significant difference between the passing rates for students in QR course under pre-adaptive and adaptive modes.

Additionally, we conducted a survey to assess students' feedback about adaptive platform along with informed consent form. We discuss the survey results below.

\subsection{Students Perceptions}

Students were asked to provide feedback on how adaptive technology helped them better understand subject materials and contributed to their success in the course. While $70 \%$ of the students who enrolled in the pre-adaptive modality expressed satisfaction about the online homework about $80 \%$ percent of the students expressed same level of satisfaction with the adaptive technology. The main point of contention was that the MyMathLab could not provide a level of ease with which they could comprehend the materials. Additionally, adaptive technology offered learn, practice and certify features that allowed students to walk through the steps and point the mistakes made in the process of problem solving. Ultimately, this approach was more effective in making students to master the contents.

In open-ended responses, students who used adaptive technology reported higher levels of satisfaction along with ease of understanding and enjoyment of working with problems compared to the other group. About $80 \%$ agreed that Hawkes Learning was easy for them to use and it helped them better understand the material of the course. Finally, $71 \%$ of these students agreed that Hawkes contributed to their success in the course. 
We list below some of the students' feedbacks received from the survey:

The strengths of this course are having Hawkes because that's what really helped me learn these problems.

One of the strengths of this course was Hawkes because that is where I feel I learned most of the information. It honestly helps you think in a different manner and a logical one. Instead of not being able to solve problems, you break them down into smaller steps to help understand them.

I think that the strengths of this course are the PowerPoint and Hawkes Learning Online. Hawkes helps so much with homework because it guides you through homework especially on problems you don't understand.

I think the homework really helped me learn the material. I consider the strengths of this course to be the homework style. I thought that the way we did the homework was very helpful because we were able to learn and practice before finishing the homework.

Hawkes learning allows you to practice and make sure that you understand every chapter. The strengths would be the overview that is presented throughout course lectures and the Hawkes learning system.

A similar survey done with the pre-adaptive group reflected relatively less satisfaction among the students. About $50 \%$ students reported their frustration about the online homework platform.

We list below some of the feedbacks received from the survey:

The MyMathLab can be a little confusing and tedious.

Sometimes I am one number away from the right answer and it really frustrates me and I am not told how to fix it. Improve the math homework. Some of the questions are unrelated to what was done in class, and it should only be on relevant questions.

\section{Conclusion and Recommendations \\ 5.1 Conclusion}

Although there is no statistically significant difference between the passing rates of students in both course modalities, the students' enthusiasm as reflected in the above feedbacks reveal that mastery-based adaptive technology by Hawkes Learning could be a valuable asset in freshmen Mathematics courses. The fact that most students were able to succeed in QR course with this technology along with their heightened enthusiasm reveal the advantage of this system. This mastery-based technology was able to help students right away whenever they faced challenges concerning problem solving. In general, this approach has reduced the widespread frustration students had in their freshmen level Mathematics courses. As an added benefit, this technology enabled students to take charge of their learning and enabled them to become better independent learners.

\subsection{Recommendations for Further Research}

We recommend more studies on the efficacy of various web-based learning systems in freshmen-level Mathematics courses as many institutions are implementing adaptive systems in order to improve teaching and learning. Furthermore, we propose extending these studies to assess the efficacy of adaptive technology in Mathematics courses beyond freshmen level.

\section{References}

Assessment and Learning in Knowledge Spaces (ALEKS). (n.d.). Retrieved from http://www.highed.aleks.com/ Bennett, J. O., \& Briggs, W. L. (2014). Using and understanding mathematics: A quantitative reasoning approach. Boston, MA: Pearson.

Chen, C. M. (2009). Personalized E-learning system with self-regulated learning assisted mechanisms for promoting learning performance. Expert Systems with Applications, 36(5):8816-8829.

Denley, K., \& Hall, M. (2016). Viewing life mathematically: A pathway to quantitative literacy. Mount Pleasant, SC: Hawkes Learning Systems.

Elrod, S. (2014). Quantitative Reasoning: The Next "Across the Curriculum” Movement. Peer Review, 16(3), 48

Hagerty, G. \& Smith, S. (2005). Using the Web-Based Interactive Software ALEKS to Enhance College Algebra. Mathematics and Computer Education, 39(3), 183-194. Retrieved June 7, 2019 from https://www.learntechlib.org/p/67912/

Hagerty, G., Smith, S., \& Goodwin, D. (2010). Redesigning College Algebra: Combining Educational Theory and Web-Based Learning to Improve Student Attitudes and Performance. Primus, 20(5), 418-437.

Hawkes Learning (2019). Retrieved from http://www.hawkeslearning.com/

Johnson, C. (March 7, 2016). Adaptive Learning Platforms: Creating a Path for Success. Retrieved from https://er.educause.edu/articles/2016/3/adaptive-learning-platforms-creating-a-path-for-success

Knewton. (2019). Retrieved from: https://www.knewton.com/

Kolowich, S. (January 25, 2013). The New Intelligence. Retrieved from https://www.insidehighered.com/news/2013/01/25/arizona-st-and-knewtons-grand-experiment-adaptivelearning 
Moosavi, S. A. (2009). A comparison of two computer-aided instruction methods with traditional instruction in freshmen college mathematics classes (Order No. 3390576). Available from ProQuest Dissertations \& Theses Global. (304829612). Retrieved from https://login.ezproxy.net.ucf.edu/login?url=http://search.proquest.com/docview/3048296 12 ? accountid $=10003$ Pearson Education

(2014).

Retrieved from http://www.pearsonmylabandmastering.com/northamerica/

O'Neil, C. (December 06, 2016). Students make gains in math placement, thanks to online adaptive learning. Retrieved from https://news.ucsc.edu/2016/12/adaptive-learning.html

Pryor, J. H., Eagan, K., Palucki Blake, L., Hurtado, S., Berdan, J., \& Case, M. H. (2012). The American Freshman: National Norms Fall 2012. Los Angeles: Higher Education Research Institute, UCLA.

Stillson, H., \& Alsup, J. (2003). Smart ALEKS ... or Not? Teaching Basic Algebra using an Online Interactive Learning System. Mathematics \& Computer Education, 37(3), 329- 340.

U.S. Department of Education, Office of Educational Technology. (2013). Expanding evidence approaches for learning in a digital world. Washington, D.C.

Wendel, H. M. (2016). Effects of Intelligent Computer-Generated Interactive Mathematics Programs on Students' Achievement and Affective Domain. Florida Institute of Technology (Doctoral dissertation). Retrieved from ProQuest Dissertation and Theses. (Accession order No. 10597671). 